\title{
Revisions for screw malposition and clinical outcomes after robot-guided lumbar fusion for spondylolisthesis
}

\author{
*Marc L. Schröder, MD, PhD, ${ }^{1}$ and Victor E. Staartjes ${ }^{1,2}$ \\ ${ }^{1}$ Department of Neurosurgery, Bergman Clinics, Naarden, The Netherlands; and ${ }^{2}$ Faculty of Medicine, University of Zurich, \\ Switzerland
}

OBJECTIVE The accuracy of robot-guided pedicle screw placement has been proven to be high, but little is known about the impact of such guidance on clinical outcomes such as the rate of revision surgeries for screw malposition. In addition, there are very few data about the impact of robot-guided fusion on patient-reported outcomes (PROs). Thus, the clinical benefit for the patient is unclear. In this study, the authors analyzed revision rates for screw malposition and changes in PROs following minimally invasive robot-guided pedicle screw fixation.

METHODS A retrospective cohort study of patients who had undergone minimally invasive posterior lumbar interbody fusion (MI-PLIF) or minimally invasive transforaminal lumbar interbody fusion was performed. Patients were followed up clinically at 6 weeks, 12 months, and 24 months after treatment and by mailed questionnaire in March 2016 as a final follow-up. Visual analog scale (VAS) scores for back and leg pain severity, Oswestry Disability Index (ODI), screw revisions, and socio-demographic factors were analyzed. A literature review was performed, comparing the incidence of intraoperative screw revisions and revision surgery for screw malposition in robot-guided, navigated, and freehand fusion procedures.

RESULTS Seventy-two patients fit the study inclusion criteria and had a mean follow up of $32 \pm 17$ months. No screws had to be revised intraoperatively, and no revision surgery for screw malposition was needed. In the literature review, the authors found a higher rate of intraoperative screw revisions in the navigated pool than in the robot-guided pool ( $p$ $<0.001$, OR 9.7). Additionally, a higher incidence of revision surgery for screw malposition was observed for freehand procedures than for the robot-guided procedures $(p<0.001$, OR 8.1). The VAS score for back pain improved significantly from $66.9 \pm 25.0$ preoperatively to $30.1 \pm 26.8$ at the final follow-up, as did the VAS score for leg pain (from $70.6 \pm 22.8$ to $24.3 \pm 28.3$ ) and ODI (from $43.4 \pm 18.3$ to $16.2 \pm 16.7$; all $p<0.001$ ). Undergoing PLIF, a high body mass index, smoking status, and a preoperative ability to work were identified as predictors of a reduction in back pain. Length of hospital stay was $2.4 \pm 1.1$ days and operating time was $161 \pm 50$ minutes. Ability to work increased from $38.9 \%$ to $78.2 \%$ of patients $(p<0.001)$ at the final follow-up, and $89.1 \%$ of patients indicated they would choose to undergo the same treatment again.

CONCLUSIONS In adults with low-grade spondylolisthesis, the data demonstrated a benefit in using robotic guidance to reduce the rate of revision surgery for screw malposition as compared with other techniques of pedicle screw insertion described in peer-reviewed publications. Larger comparative studies are required to assess differences in PROs following a minimally invasive approach in spinal fusion surgeries compared with other techniques.

https://thejns.org/doi/abs/10.3171/2017.3.FOCUS16534

KEY WORDS robot; lumbar interbody fusion; spondylolisthesis; pedicle screws; revision surgery; revision; malposition; minimally invasive

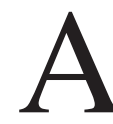
DECADE ago, minimally invasive surgery (MIS) was considered a promising development in spine treatment, yet the value of the pioneering technologies was questionable. With the growing number of surgeons experienced in MIS, the influx of evidence in favor of MIS is rapidly increasing. The published data make a compelling argument for distinct clinical benefits with MIS over open approaches in terms of blood loss, length of hospital stay, rehabilitation, cost-effectiveness, and perioperative patient comfort. ${ }^{13,31}$ Because of the limited

ABBREVIATIONS BMI = body mass index; $\mathrm{FH}=$ freehand; $\mathrm{K}$-wire = Kirschner wire; $\mathrm{MCID}=$ minimum clinically important difference; $\mathrm{MI}-\mathrm{PLIF}=$ minimally invasive posterior lumbar interbody fusion; MI-TLIF = MI transforaminal lumbar interbody fusion; MIS = minimally invasive surgery; NV = navigated; ODI = Oswestry Disability Index; PRO = patient-reported outcome; $R G$ = robot guided; VAS-BP = visual analog scale for back pain; VAS-LP = VAS for leg pain.

SUBMITTED December 9, 2016. ACCEPTED March 6, 2017.

INCLUDE WHEN CITING DOI: 10.3171/2017.3.FOCUS16534.

* Dr. Schröder and Mr. Staartjes contributed equally to this work. 
or nonexistent line-of-sight in MIS, surgeons must rely on imaging, navigation, and guidance technologies to operate in a safe and efficient manner. Therefore, a plethora of new and ever-improving navigational systems have been developed. These systems allow a consistent level of safety and accuracy on par with the results achieved by very experienced surgeons (freehand) and with a reasonably steep learning curve. ${ }^{19,34,36}$ Computer-based navigation systems were introduced to the field of spine surgery in 1995, and while they have been long established as standards in certain cranial procedures, they have not been similarly adopted in spine surgery. ${ }^{17,25}$ Designed to overcome some of the limitations of navigation-based technologies, robot-guided surgical systems have become commercially available worldwide, including systems such as SpineAssist and Renaissance (both by Mazor Robotics Ltd.) and the recently launched ROSA Spine (Medtech). These systems are rapidly challenging the gold standards. ${ }^{39}$ SpineAssist, and its upgraded version, Renaissance, mechanically restricts the surgeon's natural full range of motion at 6 degrees of freedom to 2 degrees of freedom (up and down motion and yaw in the cannula) and thus guides the surgeon to a predefined point in the anatomy, at a specific trajectory, while providing stability for drilling. To do this, the system's guidance unit moves into the trajectory based on exact preoperative planning of pedicle screw insertions, while accounting for changes in intervertebral relationships such as those attributable to distraction or cage insertion or changes between the supine patient on preoperative $\mathrm{CT}$ and the prone patient on the operating table. Robotic navigation can be very useful in instrumenting pedicles, especially in minimally invasive procedures and in anatomically challenging cases such as dysplastic, twisted, and scoliotic pedicles or in cases in which previous implants limit trajectories. Published evidence on robot-guided screw placement has demonstrated high levels of accuracy, with most studies reporting rates of around $98 \%$ of screws placed within the pedicle or with a cortical encroachment of less than $2 \mathrm{~mm}$.7,10,19,23,27,30,33,41 Although the reliability and accuracy of robot-guided spine surgery have been established, the actual benefits for the patient in terms of surgical revision rates and clinical outcomes remain unknown. Little is currently known about the impact of robot-guided fusion, relative to alternative fusion techniques, on patient-reported outcomes (PROs) or on the revision rates for screw malposition. If a screw is inserted correctly, it is inconceivable that any significant change in outcome could be produced by simply changing the method of screw navigation. The clinical result of a fusion procedure depends on various factors, but the most crucial part for a good clinical outcome remains proper decompression of the nerve roots and stabilization of the sagittal balance, assuming correct pedicle screw placement. Of course, "spinal fusion" is a rather heterogeneous term; therefore, it is difficult to find suitable cohorts for metaanalysis. As one of the first adopters of robotic guidance, we have applied it in all of our posterior lumbar fusions for more than 6 years now. In the current study, we present revision rates and clinical and socio-demographic outcomes for a homogeneous patient cohort that underwent robot-guided minimally invasive pedicle screw fixation for single-level degenerative or isthmic spondylolisthesis, with a minimum follow-up of 1 year.

\section{Methods \\ Overview}

We reviewed the medical records of patients who had undergone robot-guided minimally invasive posterior lumbar interbody fusion (MI-PLIF) or minimally invasive transforaminal lumbar interbody fusion (MI-TLIF) between 2011 and 2015. Patients were followed up clinically at 6 weeks, 12 months, and 24 months postoperatively. In March 2016, a final follow-up by means of a mailed questionnaire recorded visual analog scale (VAS) scores for back pain (VAS-BP) and leg pain (VAS-LP), Oswestry Disability Index (ODI) scores as well as socio-demographic factors and whether revision surgery had occurred. ${ }^{9}$ Our study was approved by the Dutch committee for research ethics.

\section{Study Population}

Inclusion criteria were patients of adult age with a diagnosis of spondylolisthesis confirmed by radiography and MRI. Only patients with Meyerding Grade I and II spondylolisthesis were included. ${ }^{24}$ Patients eligible for study inclusion had to have a complete preoperative record with a minimum follow-up of 12 months. Patients with a body mass index (BMI) over $33 \mathrm{~kg} / \mathrm{m}^{2}$, an American Society of Anesthesiologists score $>2$, an age over 80 years, or a diagnosis of osteoporosis were not surgically treated. Smokers were strongly advised to quit smoking before surgery. Detailed baseline patient characteristics are shown in Table 1.

\section{Literature Review of Revision Surgery}

The electronic databases of PubMed and MEDLINE were searched for literature published up to July 2016. The search strategy was based on a combination of the following terms: "robot," "robotic," "freehand," "navigation," "spine," "spinal fusion," "pedicle screw," "revision," "malposition," "misplacement," and "breaching." References in the articles found were reviewed. No restrictions for language were applied. We independently screened search results and abstracts to identify suitable literature. Inclusion criteria were studies describing placement of pedicle screws for fusion using robotic guidance, navigation (CT or fluoroscopy-assisted), or freehand techniques and reporting the proportion of patients that required revision surgery specifically for malposition of pedicle screws. Most articles additionally reported the incidence of intraoperative repositioning of pedicle screws. The revision rates were pooled by technique and weighted by study size. The $\mathrm{p}$ values comparing the robot-guided (RG) pool to the navigated (NV) and freehand $(\mathrm{FH})$ pools were assessed using Fisher's exact tests, and respective odds ratios and relative risks were calculated.

\section{Operative Technique}

Prior to surgery, 1-mm slice thickness CT scans were acquired. The surgeon created a blueprint of the pedicle 
TABLE 1. Demographic and baseline characteristics in patients who underwent minimally invasive robot-guided pedicle screw fixation

\begin{tabular}{|c|c|}
\hline Characteristic & Value \\
\hline Male sex & $50 \%$ \\
\hline Mean age (yrs) & $52.8 \pm 11.4$ \\
\hline \multicolumn{2}{|l|}{ Smoking status } \\
\hline Smoker & $31 \%$ \\
\hline Quit smoking & $24 \%$ \\
\hline Nonsmoker & $46 \%$ \\
\hline \multicolumn{2}{|l|}{ Preop ability to work } \\
\hline Fully able & $39 \%$ \\
\hline Limited & $25 \%$ \\
\hline Not able & $36 \%$ \\
\hline Mean BMI (kg/m²) & $25.9 \pm 3.5$ \\
\hline History of back \& leg pain (mos) & $10.7 \pm 5.3$ \\
\hline Prior back surgery at index level & $24 \%$ \\
\hline \multicolumn{2}{|l|}{ Type of work } \\
\hline Employed & $53 \%$ \\
\hline Self-employed & $13 \%$ \\
\hline Retired & $11 \%$ \\
\hline Housework & $10 \%$ \\
\hline Disablement insurance & $8 \%$ \\
\hline Jobless & $6 \%$ \\
\hline VAS-BP score & $66.9 \pm 25$ \\
\hline VAS-LP score & $70.6 \pm 22.8$ \\
\hline ODI score & $43.4 \pm 18.3$ \\
\hline
\end{tabular}

Values expressed as the mean \pm standard deviation, unless indicated otherwise.

screw trajectories on the workstation, taking into account the individual variations in vertebral anatomy, entry point, screw length, diameter, and angulation. The patient was placed prone, and the correct spinal level was identified fluoroscopically. In cases of unilateral radiculopathy, we opted for MI-TLIF. In these cases, a paramedian incision was made, and the facet joint was exposed through a 2.5$\mathrm{cm}$ tubular working channel. Facet joint and ligamentum flavum hypertrophy were resected. In cases of bilateral radiculopathy, we opted for MI-PLIF. These cases were performed via a mini-open midline approach used for bilateral decompression. In both methods the intervertebral disc space was cleared, and the endplates were prepared for fusion. A Crescent or Capstone cage (Medtronic plc.) was filled with autograft bone and inserted. The remaining disc space was filled with autograft bone and demineralized bone matrix (Nanostim or Grafton, Medtronic plc.), if needed. The SpineAssist's Hover-T mounting frame (Fig. 1) was attached to a spinous process and the posterior aspects of the iliac crests. A 3D fiducial array was attached. Anteroposterior and $60^{\circ}$ oblique fluoroscopic images were taken and automatically matched to the preoperative CT. Once the surgeon confirmed correct registration for each vertebra, the robotic guidance unit was dispatched to the preoperatively planned trajectories. An incision was made

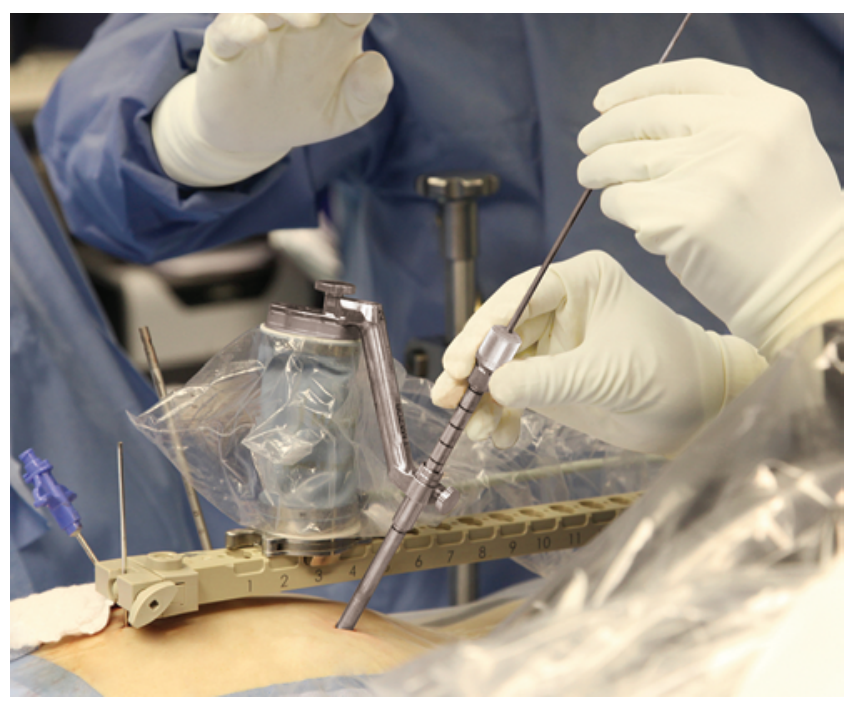

FIG. 1. The SpineAssist robot was mounted on the Hover-T frame, and K-wires were inserted through the guidance cannula. Copyright Mazor Robotics. Published with permission.

through the robot's cannula, and a trocar was advanced onto the desired entry point. The pedicle was drilled using a 3-mm-diameter drill bit limited to a depth of $30 \mathrm{~mm}$ by a positive stopper. Kirschner (K)-wires were introduced as previously described. ${ }^{10,30,40}$ A pedicle screw (Sextant, Medtronic plc.) was inserted percutaneously over the Kwire. This process was repeated for all trajectories. Fluoroscopic control was used to confirm optimal implant placement. Reduction was achieved, if necessary, and two curved rods were inserted percutaneously. Figure 2 shows representative pre- and postoperative images.

\section{Data and Statistics}

Continuous variables were reported as the mean \pm standard deviation, and categorical variables as percentages. Change scores from baseline were calculated for VAS and ODI. The minimum clinically important difference (MCID) was defined as $\geq 30 \%$ improvement in the respective score. ${ }^{28}$ Data were analyzed using IBM SPSS Statistics version 23.0 (IBM Corp.). The Shapiro-Wilk test was used to test for normality. All outcome scores were nonnormally distributed, so Mann-Whitney and Wilcoxon tests were used. Predictors of MCID were analyzed using binomial logistic regression. Proportional values were compared using Fisher's exact test. Significance was set at $\mathrm{p} \leq 0.05$.

\section{Results}

Among the 94 patient records matching most of the inclusion criteria, 72 had completed a follow-up $\geq 12$ months. Preoperatively, 68 patients $(94.4 \%)$ experienced leg pain and 69 patients (95.8\%) had back pain. Seventeen patients $(23.6 \%)$ had undergone previous surgery at the index level, all of them discectomy. The average skinto-skin time of surgery was $161 \pm 50$ minutes. Perioperative and outcome data are presented in Table 2. None of the pedicle screws required intraoperative repositioning, 

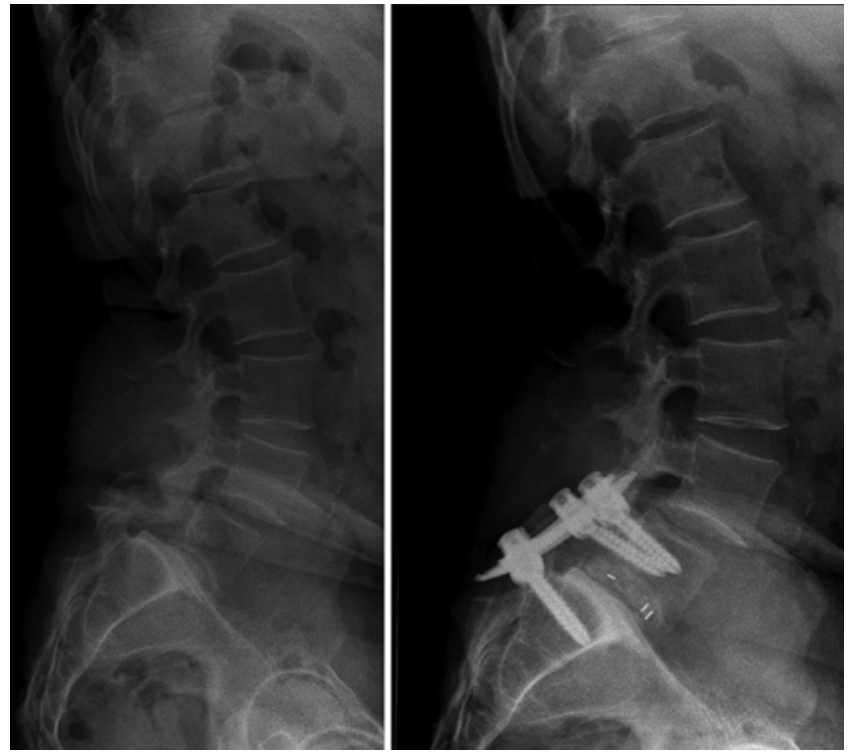

FIG. 2. Preoperative radiograph (left) obtained in a patient presenting with Grade II spondylolisthesis. Minimally invasive robot-guided pedicle screw fixation was performed. Postoperative lateral radiograph (right) shows proper pedicle screw placement and reduction of the slippage.

and conversion to an open procedure was never required. There were no implant-related revisions or complications, which were assessed clinically rather than on postoperative radiological studies, to avoid excessive radiation exposure. Two patients had facet cysts removed after the original surgery, and one patient required additional fixation on an adjacent level, which was performed elsewhere, equaling an overall non-screw-related revision rate of 4.2\%. Apart from 5 durotomies and 2 transient partial extensor pareses (9.7\%), no other complications were observed. The VAS-BP decreased by $49.3 \%$ from $66.9 \pm 25.0$ preoperatively to $30.1 \pm 26.8$ at the final follow-up (mean follow-up $32 \pm 17$ months), whereas VAS-LP decreased by $63.4 \%$ from $70.6 \pm 22.8$ to $24.3 \pm 28.3$ (both $\mathrm{p}<0.001$ ). The ODI scores decreased by $61.2 \%$ from $43.4 \pm 18.3$ to $16.2 \pm 16.7$ ( $\mathrm{p}<0.001)$. The MCID was achieved in $68.1 \%$ of patients for VAS-BP, in 75\% for VAS-LP, and in $77.8 \%$ for ODI. Figure 3 shows the outcome scores during the follow-up period. Ability to work increased from $38.9 \%$ to $78.2 \%$ ( $\mathrm{p}<0.001$ ) at the final follow-up. The use of analgesic medication was fully discontinued by $60 \%$ of the patients at the final follow-up, although $20 \%$ still resorted to such medication daily. Postoperatively, $63.6 \%$ of patients were satisfied or highly satisfied, and $89.1 \%$ would choose to undergo the same treatment again. Figure 4 shows work status and use of analgesic medication during follow-up. Table 3 provides an overview of the baseline variables of the logistic regression models to predict achievement of an MCID. An MI-PLIF (OR 10.5, 95\% CI 1.1-96.1, $\mathrm{p}=$ 0.038 ), a high BMI (OR 1.5, 95\% CI 1.1-2, p = 0.010), a status of having quit smoking (OR 48.3, 95\% CI 2.6$896.4, p=0.009$ ), and a full ability to work preoperatively (OR 34, 95\% CI 2.8-408, $\mathrm{p}=0.005$ ) were significant predictors for achieving an MCID in VAS-BP. The only significant baseline predictor for clinical success in VAS-LP
TABLE 2. Perioperative data and clinical outcomes

\begin{tabular}{|c|c|}
\hline Characteristic & Value \\
\hline \multicolumn{2}{|l|}{ Type of surgery } \\
\hline MI-TLIF & $54 \%$ \\
\hline MI-PLIF & $46 \%$ \\
\hline \multicolumn{2}{|l|}{ Meyerding grade* } \\
\hline Grade I anterolisthesis & $82 \%$ \\
\hline Grade II anterolisthesis & $14 \%$ \\
\hline Grade I retrolisthesis & $4 \%$ \\
\hline \multicolumn{2}{|l|}{ Index level } \\
\hline L2-3 & $1 \%$ \\
\hline L3-4 & $4 \%$ \\
\hline L4-5 & $53 \%$ \\
\hline L5-S1 & $42 \%$ \\
\hline \multicolumn{2}{|l|}{ Periop data } \\
\hline Estimated blood loss (ml) & $336 \pm 262$ \\
\hline Dose area product (mGy $\left.\mathrm{cm}^{2}\right)$ & $306 \pm 123$ \\
\hline Duration of surgery (min) & $161 \pm 50$ \\
\hline Length of hospital stay (days) & $2.4 \pm 1.1$ \\
\hline \multicolumn{2}{|l|}{ Change scores at final FU } \\
\hline VAS-BP & $36.8 \pm 28.6$ \\
\hline VAS-LP & $46.3 \pm 29.4$ \\
\hline ODI & $27.2 \pm 21.1$ \\
\hline
\end{tabular}

$\mathrm{FU}=$ follow-up.

* Meyerding grades of spondylolisthesis: Grade I signifies $<25 \%$ slippage and Grade II signifies 25\%-50\% slippage.

was a high BMI (OR 1.4, 95\% CI 1-1.9, $\mathrm{p}=0.035)$. No significant predictors were found for achieving an MCID in ODI scores. The Meyerding grade of slippage did not influence outcomes.

Results of the literature review are presented in Table 4. Originally, 616 articles were found, and we both screened the titles and abstracts. Fourteen suitable articles were found and included. $3,6,18,20-22,33-35,37,38,41,43,44$ Data from Ryang et al., ${ }^{34}$ Kantelhardt et al., ${ }^{20}$ and Bydon et al. ${ }^{6}$ were identified as outliers. Table 5 summarizes the meta-analysis of screw revision rates from the included studies. Intraoperative screw repositions were significantly higher for NV versus RG, even after removing outliers ( $\mathrm{p}<0.001$, OR 9.7, 95\% CI 2.9-32.2). The same cannot be said for FH versus RG; that is, there was no significant difference between the two pools after removing the outliers ( $\mathrm{p}=$ 0.36 , OR $0.3,95 \%$ CI 0.1-3.0). When looking at the rate of revision surgery for pedicle screw malposition, revision rates were significantly higher for $\mathrm{FH}$ versus $\mathrm{RG}$, even after removing outliers ( $\mathrm{p}<0.001$, OR 8.1, 95\% CI 2-33.3). There was no significant difference between NV and RG $(\mathrm{p}=0.27$, OR 2.7, 95\% CI 0.6-11.9).

\section{Discussion}

\section{Screw Malposition and Revisions}

This is the first analysis of revision rates for screw malposition in robot-guided thoracolumbar fusions. Established techniques lead to radiologically accurate place- 


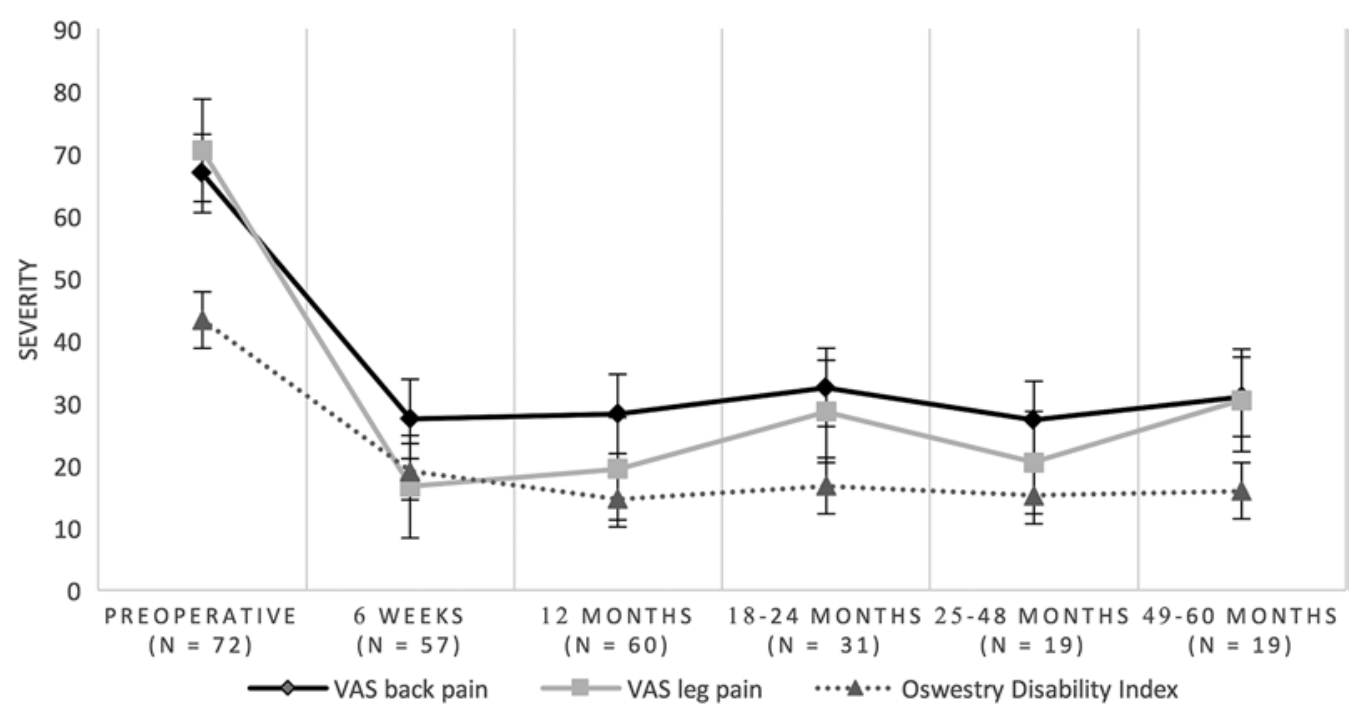

FIG. 3. Development of outcome scores throughout the follow-up period.

ment of screws in 69\%-94\% of cases using freehand techniques, $81 \%-92 \%$ of cases using fluoroscopically guided techniques, and $89 \%-100 \%$ of cases using CT-based navigations. ${ }^{11}$ The accuracy of screw placement with robotic guidance has been studied extensively in the literature with results ranging from $85 \%$ to $98.3 \%$ of screws placed accurately and most rates fluctuating around $98 \% .7,10,30,33,41$ Radiological screw malposition between $1.1 \%$ and $28.2 \%$ is reported in the literature; however, not every screw malposition necessitates surgical revision. ${ }^{14,26}$ When a screw malposition is observed intraoperatively, the screw is usually repositioned immediately. This prolongs operative time, adds radiation and tissue trauma, and has been shown to reduce screw pullout strength. ${ }^{12}$ Given these factors, correct initial screw placement seems a reliable indicator for clinical effectiveness and should be seriously considered when comparing navigational systems. In our meta-analysis, when comparing RG to NV pools, the number of intraoperative revisions was significantly higher in the NV pool (RR 9.1). This is unlikely to be caused by inaccuracy but instead confirms that when using navigation via intraoperative CT or 3D fluoroscopy, grave screw malposition can be detected early on, often leading to immediate revision. As expected, no difference was observed in the incidence of intraoperative revisions between $\mathrm{RG}$ and FH. Revision surgery is an important clinical parameter because screw malpositions can cause neurological deficits, pedicular fracture, or pain. Moreover, revision surgery is accompanied by higher costs. ${ }^{1,18}$ Given these factors, it is paramount to minimize the number of screw revision surgeries. According to our literature review, the rate of revision surgery for screw malposition was significantly higher in the FH pool than in the RG pool, regardless of outliers, with an RR of 7.9 without the outliers. It is noteworthy that

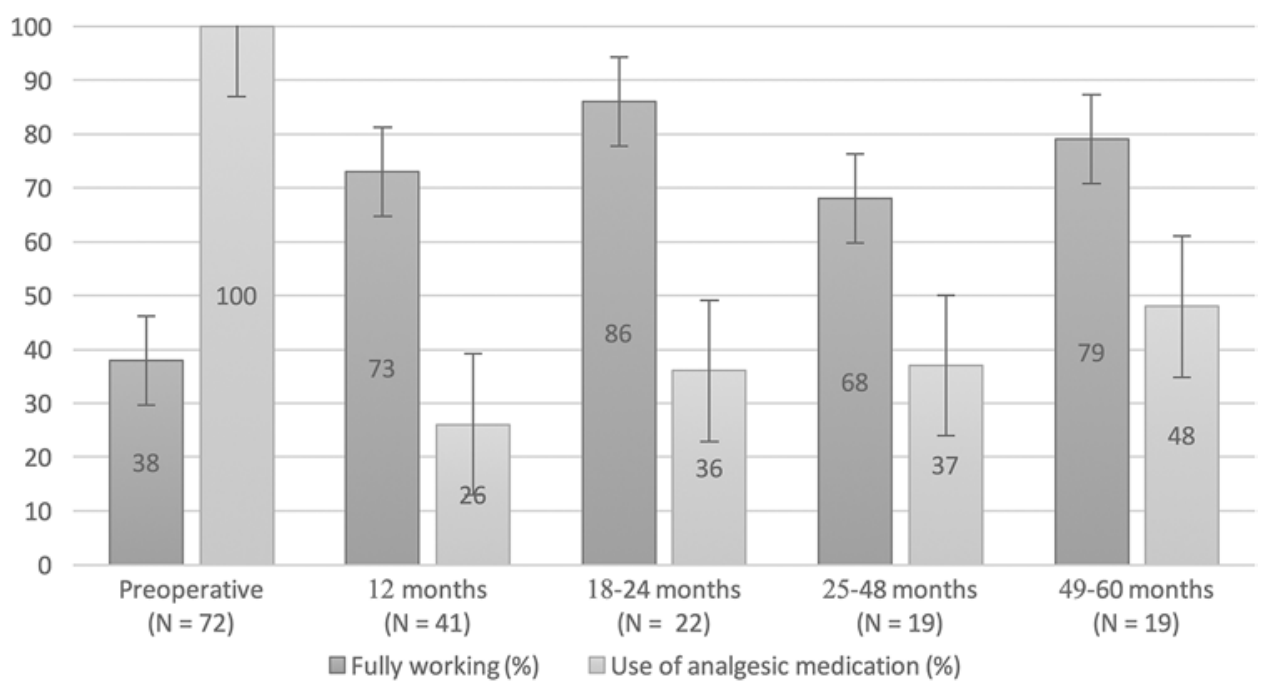

FIG. 4. Work status and use of analgesic medication throughout the follow-up period. 
TABLE 3. Predictors for clinical success in outcome variables*

\begin{tabular}{llll}
\hline \multicolumn{1}{c}{ Predictor } & VAS-BP $\mathrm{p}$ Value & VAS-LP $\mathrm{p}$ Value & ODI $\mathrm{p}$ Value \\
\hline Ability to work & $0.02 \dagger$ & 0.15 & 0.1 \\
\hline Age & 0.54 & 0.95 & 0.09 \\
\hline $\mathrm{BMI}$ & $0.01 \dagger$ & $0.035 \dagger$ & 0.11 \\
\hline Grade of slippage & 0.96 & 0.78 & 0.2 \\
\hline Index level & 0.9 & 0.22 & 0.55 \\
\hline Sex & 0.08 & 0.64 & 0.08 \\
\hline Smoking status & $0.033 \dagger$ & 0.96 & 0.13 \\
\hline Surgery type & $0.038 \dagger$ & 0.3 & 0.23 \\
\hline Type of work & 0.29 & 0.41 & 0.32 \\
\hline
\end{tabular}

* Clinical success was defined as a MCID of $\geq 30 \%$ improvement in the respective score.

$\dagger p \leq 0.05$

with an RR of 2.7, the NV technique tended toward more revisions in which many of the malpositions were detected intraoperatively and immediately revised. Therefore, we observed no significant difference in postoperative revision rates between the NV and RG pools.

Computed tomography-based navigation certainly has an important advantage over robotic navigation in terms of real-time radiological imaging. However, this also means the surgeon must design the fixation structure in real-time, which can add stress, especially in complex cases. Robotic guidance circumvents this problem by providing the possibility of making a preoperative blueprint of the ideal fixation. This blueprint can be drawn in the office prior to surgery while even accounting for perfect screw length, thickness, and angulation. With this done, even in the most challenging cases, the only thing left to do is for the surgeon to place the pedicle screws while being guided by the workstation. Additionally, CT-based navigation relies on the surgeon as both gross and fine positioner of the instrumentation, relying on the 6 degrees of freedom of the human hand. With robotic guidance, the electromechanical arm physically holds a cannula over the desired trajectory, providing the surgeon with a stable working channel, which allows for 2 degrees of freedom (depth and clockwise/counterclockwise yaw), relieving the surgeon from the role of instrumentation positioner. Thus, the surgeon can look directly at his hands rather than at a virtual representation of the tools displayed in 3 or 4 planes overhead.

\section{Clinical Outcomes}

Currently, very few PROs of robot-guided fusions have been published. This study presents the longest follow-up of MI-T/PLIF for spondylolisthesis. The improvement in VAS-BP, VAS-LP, and ODI scores closely resembles findings in the literature and was mostly sustained without significant changes during follow-up., ${ }^{2,4,16,29,42}$ The only exception was a worsening of VAS-LP scores between 12 and 24 months $(p=0.026)$, although this worsening was found in another study as well. ${ }^{15}$ We thought that this increase in leg pain could explain the increase in the use of analgesic medication over the same time span, but the two factors were not correlated $(p=0.78)$. Note that surgery duration

TABLE 4. Results of the literature search for screw revision rates

\begin{tabular}{|c|c|c|c|}
\hline Authors \& Year & Technique Used (no. of patients) & Intraop Screw Revision (\%) & Screw-Related Revision Surgery (\%) \\
\hline Current cohort & $\mathrm{RG}(72)$ & 0 & 0 \\
\hline van Dijk et al., 2015 & $\mathrm{RG}(112)$ & 0 & 0 \\
\hline Kantelhardt et al., 2011 & RG (49) & 0 & 4.1 \\
\hline Ringel et al., 2012 & $\mathrm{RG}(146)$ & 0 & 0 \\
\hline Schatlo et al., 2014 & $\mathrm{RG}(55)$ & 5.5 & 0 \\
\hline Zausinger et al., 2009 & NV-CT (94) & 8.5 & 0 \\
\hline Zausinger et al., 2009 & NV-FL (182) & - & 4.4 \\
\hline Santos et al., 2015 & NV-CT (199) & 4.6 & 0 \\
\hline Hecht et al., 2011 & NV-CT (87) & 8 & 0 \\
\hline Ryang et al., 2015 & NV-FL (145) & $26.2^{*}$ & 0.7 \\
\hline Waschke et al., 2013 & NV-CT (505) & - & 1.2 \\
\hline Kantelhardt et al., 2011 & $\mathrm{FH}(49)$ & 0 & $12.2^{*}$ \\
\hline Ringel et al., 2012 & $\mathrm{FH}(152)$ & 0 & 0.7 \\
\hline Schatlo et al., 2014 & $\mathrm{FH}(40)$ & 0 & 2.5 \\
\hline Waschke et al., 2013 & $\mathrm{FH}(501)$ & - & 4.4 \\
\hline Koktekir et al., 2014 & $\mathrm{FH}(198)$ & - & 7.6 \\
\hline Bydon et al., 2014 & $\mathrm{FH}(203)$ & $35.5^{*}$ & 1 \\
\hline Soriano-Sánchez et al., 2015 & $\mathrm{FH}(125)$ & 0 & 0 \\
\hline Kim et al., 2011 & $\mathrm{FH}(110)$ & - & 1.8 \\
\hline Amato et al., 2010 & $\mathrm{FH}(102)$ & 1 & 8.8 \\
\hline
\end{tabular}

NV-CT = CT navigated; NV-FL = fluoroscopically navigated.

${ }^{*}$ These reports were identified as outliers. 
TABLE 5. Literature review of intraoperative screw revisions and revision surgery for screw malposition

\begin{tabular}{|c|c|c|c|c|c|c|c|c|}
\hline \multirow[b]{2}{*}{ Pool } & \multicolumn{4}{|c|}{ Intraop Screw Revision } & \multicolumn{4}{|c|}{ Revision Surgery for Screw Malposition } \\
\hline & $\begin{array}{c}\text { Weighted } \\
\text { Proportion (\%) }\end{array}$ & $\begin{array}{c}p \\
\text { Value* }^{*}\end{array}$ & $\begin{array}{c}\text { OR } \\
(95 \% \mathrm{Cl})^{*}\end{array}$ & $\begin{array}{c}\text { RR } \\
(95 \% \mathrm{Cl})^{*}\end{array}$ & $\begin{array}{c}\text { Weighted } \\
\text { Proportion (\%) }\end{array}$ & $\begin{array}{c}p \\
\text { Value }^{*}\end{array}$ & $\begin{array}{c}\text { OR } \\
(95 \% \mathrm{Cl})^{*}\end{array}$ & $\begin{array}{c}\mathrm{RR} \\
(95 \% \mathrm{Cl})^{*}\end{array}$ \\
\hline RG & 0.7 & - & - & - & 0.5 & - & - & - \\
\hline NV & 11.8 & $<0.001 \dagger$ & $19.2(62.5-6.0)$ & $17.1(5.4-54.0)$ & 1.2 & 0.27 & $2.7(0.6-11.9)$ & $2.7(0.6-11.7)$ \\
\hline NV: outliers removed & 6.3 & $<0.001 \uparrow$ & $9.7(2.9-32.3)$ & $9.1(2.8-30.1)$ & - & - & - & - \\
\hline $\mathrm{FH}$ & 10.9 & $<0.001 \dagger$ & $17.5(5.5-55.6)$ & $15.7(5.0-49.6)$ & 3.9 & $<0.001 \dagger$ & $8.8(2.1-35.7)$ & $8.5(2.1-34.7)$ \\
\hline FH: outliers removed & 0.2 & 0.36 & $0.3(0.1-3.0)$ & $0.3(0.1-3.0)$ & 3.6 & $<0.001 \dagger$ & $8.1(2.0-33.3)$ & $7.9(1.9-32.2)$ \\
\hline
\end{tabular}

* $p$ values calculated using Fisher's exact test, and odds ratios and relative risks are provided, as compared to the RG pool.

$\dagger p \leq 0.05$.

(161 minutes) and length of stay (2.4 days) were shorter in our cohort than that reported in the literature, whereas blood loss was slightly above average. The latter finding is likely attributable to the fact that blood loss under 200 $\mathrm{ml}$ in our cohort was often not recorded. Our overall nonscrew-related revision rate of $4.2 \%$ was considerably lower than other reported rates of up to $23.3 \%$. $2,4,16,29,42^{2}$

\section{Socio-Demographic Factors}

Patients with a BMI $\geq 33 \mathrm{~kg} / \mathrm{m}^{2}$ were required to lose weight, and smokers were instructed to quit smoking before the procedure. Surprisingly, in our cohort a high BMI correlated with a good outcome. We did not find any supportive evidence in the literature. In fact, it is contradictory to data from the Spine Patient Outcomes Research Trial (SPORT), which states that obesity correlates with inferior outcomes. ${ }^{32}$ In our study, "quit smoking" was defined as having quit smoking before the first contact with the surgeon. Just as in our cohort $(\mathrm{p}=0.033)$, Behrend et al. ${ }^{5}$ found smoking cessation to be a strong predictor of a good outcome in a study comprising 5333 spinal patients who underwent surgery. These effects are difficult to explain, but we think that losing weight and stopping smoking may be lifestyle-changing motivational factors that can lead to improved satisfaction and outcomes. Similarly, patients who were still fully capable of working preoperatively may have stronger coping abilities and better social resources, allowing for fast and thorough rehabilitation. This finding is supported by Ekman et al., ${ }^{8}$ who found working status to be the strongest predictor of a positive outcome.

\section{Study Limitations}

This retrospective analysis of prospectively collected data is limited by the absence of a control group and randomization. In our review of revision rates in the literature, we found studies that were comparable to our cohort study in terms of indications and demographics, but we did not look at the effect of differences in surgical techniques or propensity matching. Furthermore, our conclusion could be prone to common weaknesses of meta-analyses. Prospective controlled trials, preferably randomized, are needed to validate our findings of differences in revision rates and PROs between robotic guidance and freehand or navigation techniques. Finally, we limited the scope of our study to single-level Meyerding Grade I and II spondylolisthesis; therefore, conclusions should not be drawn regarding the outcomes of robot-guided instrumentation for other indications.

\section{Conclusions}

Although robot-guided surgery will not replace the surgeon anytime soon, software and hardware have now advanced to the point where screw trajectories can be navigated even more precisely than by an experienced surgeon's hand. We present a first analysis of screw revision rates and reported PROs from a homogeneous group of patients that underwent robot-guided single-level fusions. As yet, little can be said about equality of outcomes in robot-guided fusion versus other standards. However, given our literature review, we find a potential benefit in using robotic guidance to reduce the rate of revision surgery for screw malposition as compared with other techniques of pedicle screw placement. We are currently launching an international, multicenter, randomized controlled trial to validate our findings.

\section{References}

1. Adogwa O, Owens R, Karikari I, Agarwal V, Gottfried ON, Bagley CA, et al: Revision lumbar surgery in elderly patients with symptomatic pseudarthrosis, adjacent-segment disease, or same-level recurrent stenosis. Part 2. A cost-effectiveness analysis: clinical article. J Neurosurg Spine 18:147-153, 2013

2. Adogwa O, Parker SL, Bydon A, Cheng J, McGirt MJ: Comparative effectiveness of minimally invasive versus open transforaminal lumbar interbody fusion: 2-year assessment of narcotic use, return to work, disability, and quality of life. J Spinal Disord Tech 24:479-484, 2011

3. Amato V, Giannachi L, Irace C, Corona C: Accuracy of pedicle screw placement in the lumbosacral spine using conventional technique: computed tomography postoperative assessment in 102 consecutive patients. J Neurosurg Spine 12:306-313, 2010

4. Archavlis E, Carvi y Nievas M: Comparison of minimally invasive fusion and instrumentation versus open surgery for severe stenotic spondylolisthesis with high-grade facet joint osteoarthritis. Eur Spine J 22:1731-1740, 2013

5. Behrend C, Prasarn M, Coyne E, Horodyski M, Wright J, Rechtine GR: Smoking cessation related to improved patientreported pain scores following spinal care. J Bone Joint Surg Am 94:2161-2166, 2012 
6. Bydon M, Xu R, Amin AG, Macki M, Kaloostian P, Sciubba DM, et al: Safety and efficacy of pedicle screw placement using intraoperative computed tomography: consecutive series of 1148 pedicle screws. J Neurosurg Spine 21:320-328, 2014

7. Devito DP, Kaplan L, Dietl R, Pfeiffer M, Horne D, Silberstein B, et al: Clinical acceptance and accuracy assessment of spinal implants guided with SpineAssist surgical robot: retrospective study. Spine (Phila Pa 1976) 35:2109-2115, 2010 [Erratum in Spine (Phila Pa 1976) 36:91, 2011]

8. Ekman P, Möller H, Hedlund R: Predictive factors for the outcome of fusion in adult isthmic spondylolisthesis. Spine (Phila Pa 1976) 34:1204-1210, 2009

9. Fairbank JC, Couper J, Davies JB, O'Brien JP: The Oswestry low back pain disability questionnaire. Physiotherapy 66:271-273, 1980

10. Fujishiro T, Nakaya Y, Fukumoto S, Adachi S, Nakano A, Fujiwara K, et al: Accuracy of pedicle screw placement with robotic guidance system: a cadaveric study. Spine (Phila Pa 1976) 40:1882-1889, 2015

11. Gelalis ID, Paschos NK, Pakos EE, Politis AN, Arnaoutoglou CM, Karageorgos AC, et al: Accuracy of pedicle screw placement: a systematic review of prospective in vivo studies comparing free hand, fluoroscopy guidance and navigation techniques. Eur Spine J 21:247-255, 2012

12. Goda Y, Higashino K, Toki S, Suzuki D, Kobayashi T, Matsuura T, et al: The pullout strength of pedicle screws following redirection after lateral wall breach or end-plate breach. Spine (Phila Pa 1976) 41:1218-1223, 2016

13. Goldstein CL, Phillips FM, Rampersaud YR: Comparative effectiveness and economic evaluations of open versus minimally invasive posterior or transforaminal lumbar interbody fusion: a systematic review. Spine (Phila Pa 1976) 41 (Suppl 8):S74-S89, 2016

14. Greiner-Perth R, Boehm H, Allam Y, Elsaghir H, Franke J: Reoperation rate after instrumented posterior lumbar interbody fusion: a report on 1680 cases. Spine (Phila Pa 1976) 29:2516-2520, 2004

15. Greiner-Perth R, Sellhast N, Perler G, Dietrich D, Staub LP, Röder C: Dynamic posterior stabilization for degenerative lumbar spine disease: a large consecutive case series with long-term follow-up by additional postal survey. Eur Spine J 25:2563-2570, 2016 (Erratum in Eur Spine J 25:2563-2570, 2016)

16. Harris EB, Sayadipour A, Massey P, Duplantier NL, Anderson DG: Mini-open versus open decompression and fusion for lumbar degenerative spondylolisthesis with stenosis. Am J Orthop 40:E257-E261, 2011

17. Härtl R, Lam KS, Wang J, Korge A, Kandziora F, Audigé L: Worldwide survey on the use of navigation in spine surgery. World Neurosurg 79:162-172, 2013

18. Hecht AC, Koehler SM, Laudone JC, Jenkins A, Qureshi S: Is intraoperative $\mathrm{CT}$ of posterior cervical spine instrumentation cost-effective and does it reduce complications? Clin Orthop Relat Res 469:1035-1041, 2011

19. Hu X, Lieberman IH: What is the learning curve for roboticassisted pedicle screw placement in spine surgery? Clin Orthop Relat Res 472:1839-1844, 2014

20. Kantelhardt SR, Martinez R, Baerwinkel S, Burger R, Giese A, Rohde V: Perioperative course and accuracy of screw positioning in conventional, open robotic-guided and percutaneous robotic-guided, pedicle screw placement. Eur Spine J 20:860-868, 2011

21. Kim MC, Chung HT, Cho JL, Kim DJ, Chung NS: Factors affecting the accurate placement of percutaneous pedicle screws during minimally invasive transforaminal lumbar interbody fusion. Eur Spine J 20:1635-1643, 2011

22. Koktekir E, Ceylan D, Tatarli N, Karabagli H, Recber F, Akdemir G: Accuracy of fluoroscopically-assisted pedicle screw placement: analysis of 1,218 screws in 198 patients. Spine J 14:1702-1708, 2014

23. Kuo KL, Su YF, Wu CH, Tsai CY, Chang CH, Lin CL, et al: Assessing the intraoperative accuracy of pedicle screw placement by using a bone-mounted miniature robot system through secondary registration. PLoS One 11:e0153235, 2016

24. Meyerding HW: Spondylolisthesis; surgical fusion of lumbosacral portion of spinal column and interarticular facets; use of autogenous bone grafts for relief of disabling backache. J Int Coll Surg 26:566-591, 1956

25. Nolte LP, Zamorano L, Visarius H, Berlemann U, Langlotz F, Arm E, et al: Clinical evaluation of a system for precision enhancement in spine surgery. Clin Biomech (Bristol, Avon) 10:293-303, 1995

26. Oh HS, Kim JS, Lee SH, Liu WC, Hong SW: Comparison between the accuracy of percutaneous and open pedicle screw fixations in lumbosacral fusion. Spine J 13:1751-1757, 2013

27. Onen MR, Simsek M, Naderi S: Robotic spine surgery: a preliminary report. Turk Neurosurg 24:512-518, 2014

28. Ostelo RWJG, Deyo RA, Stratford P, Waddell G, Croft P, Von Korff M, et al: Interpreting change scores for pain and functional status in low back pain: towards international consensus regarding minimal important change. Spine (Phila Pa 1976) 33:90-94, 2008

29. Parker SL, Mendenhall SK, Shau DN, Zuckerman SL, Godil SS, Cheng JS, et al: Minimally invasive versus open transforaminal lumbar interbody fusion for degenerative spondylolisthesis: comparative effectiveness and cost-utility analysis. World Neurosurg 82:230-238, 2014

30. Pechlivanis I, Kiriyanthan G, Engelhardt M, Scholz M, Lücke S, Harders A, et al: Percutaneous placement of pedicle screws in the lumbar spine using a bone mounted miniature robotic system: first experiences and accuracy of screw placement. Spine (Phila Pa 1976) 34:392-398, 2009

31. Phillips FM, Cheng I, Rampersaud YR, Akbarnia BA, Pimenta L, Rodgers WB, et al: Breaking through the "glass ceiling" of minimally invasive spine surgery. Spine (Phila Pa 1976) 41 (Suppl 8):S39-S43, 2016

32. Rihn JA, Radcliff K, Hilibrand AS, Anderson DT, Zhao W, Lurie J, et al: Does obesity affect outcomes of treatment for lumbar stenosis and degenerative spondylolisthesis? Analysis of the Spine Patient Outcomes Research Trial (SPORT). Spine (Phila Pa 1976) 37:1933-1946, 2012

33. Ringel F, Stüer C, Reinke A, Preuss A, Behr M, Auer F, et al: Accuracy of robot-assisted placement of lumbar and sacral pedicle screws: a prospective randomized comparison to conventional freehand screw implantation. Spine (Phila Pa 1976) 37:E496-E501, 2012

34. Ryang YM, Villard J, Obermüller T, Friedrich B, Wolf P, Gempt J, et al: Learning curve of 3D fluoroscopy imageguided pedicle screw placement in the thoracolumbar spine. Spine J 15:467-476, 2015

35. Santos ERG, Sembrano JN, Yson SC, Polly DW Jr: Comparison of open and percutaneous lumbar pedicle screw revision rate using 3-D image guidance and intraoperative CT. Orthopedics 38:e129-e134, 2015

36. Schatlo B, Martinez R, Alaid A, von Eckardstein K, Akhavan-Sigari R, Hahn A, et al: Unskilled unawareness and the learning curve in robotic spine surgery. Acta Neurochir (Wien) 157:1819-1823, 2015

37. Schatlo B, Molliqaj G, Cuvinciuc V, Kotowski M, Schaller $\mathrm{K}$, Tessitore E: Safety and accuracy of robot-assisted versus fluoroscopy-guided pedicle screw insertion for degenerative diseases of the lumbar spine: a matched cohort comparison. J Neurosurg Spine 20:636-643, 2014

38. Soriano-Sánchez JA, Ortega-Porcayo LA, Gutiérrez-Partida CF, Ramírez-Barrios LR, Ortíz-Leyva RU, Rodríguez-García $\mathrm{M}$, et al: Fluoroscopy-guided pedicle screw accuracy with a 
mini-open approach: a tomographic evaluation of 470 screws in 125 patients. Int J Spine Surg 9:54, 2015

39. Stüer C, Ringel F, Stoffel M, Reinke A, Behr M, Meyer B: Robotic technology in spine surgery: current applications and future developments. Acta Neurochir Suppl 109:241-245, 2011

40. Togawa D, Kayanja MM, Reinhardt MK, Shoham M, Balter A, Friedlander A, et al: Bone-mounted miniature robotic guidance for pedicle screw and translaminar facet screw placement: part 2-Evaluation of system accuracy. Neurosurgery 60:ONS129-ONS139, 2007

41. van Dijk JD, van den Ende RPJ, Stramigioli S, Köchling M, Höss N: Clinical pedicle screw accuracy and deviation from planning in robot-guided spine surgery: robot-guided pedicle screw accuracy. Spine (Phila Pa 1976) 40:E986-E991, 2015

42. Wang J, Zhou Y, Zhang ZF, Li CQ, Zheng WJ, Liu J: Comparison of one-level minimally invasive and open transforaminal lumbar interbody fusion in degenerative and isthmic spondylolisthesis grades 1 and 2. Eur Spine J 19:1780-1784, 2010

43. Waschke A, Walter J, Duenisch P, Reichart R, Kalff R, Ewald $\mathrm{C}$ : CT-navigation versus fluoroscopy-guided placement of pedicle screws at the thoracolumbar spine: single center experience of 4,500 screws. Eur Spine J 22:654-660, 2013
44. Zausinger S, Scheder B, Uhl E, Heigl T, Morhard D, Tonn JC: Intraoperative computed tomography with integrated navigation system in spinal stabilizations. Spine (Phila Pa 1976) 34:2919-2926, 2009

\section{Disclosures}

Dr. Schröder is a consultant for Mazor Robotics Ltd.

\section{Author Contributions}

Conception and design: both authors. Acquisition of data: both authors. Analysis and interpretation of data: both authors. Drafting the article: Staartjes. Critically revising the article: both authors. Reviewed submitted version of manuscript: both authors. Approved the final version of the manuscript on behalf of both authors: Schröder. Statistical analysis: Staartjes. Administrative/ technical/material support: both authors. Study supervision: both authors.

\section{Correspondence}

Marc L. Schröder, c/o Bergman Clinics, Naarden, Rijksweg 69, Naarden 1411 GE, The Netherlands. email: m.schroder@bergman clinics.nl. 